\title{
Incidência e localização de fraturas osteocondrais “chip" na região rádio cárpica de cavalos Puro Sangue Inglês em atividade turfísta
}

\author{
Incidence and locations of osteochondral chip fractures in Thoroughbred \\ racing houses' carpus
}

\author{
Daniel Augusto Barroso Lessa ${ }^{1}$, Luis Flávio Geo de Siqueira ${ }^{2}$, Ricardo Antônio Leitão da Silva ${ }^{3}$
}

\section{Resumo}

Os autores registram a incidência e localização de 30 casos de fraturas osteocondrais "chip" na região rádio cárpica de cavalos Puro Sangue Inglês, com idade variando entre 2 e 6 anos, e concluem que o membro direito apresentou maior ocorrência. Os ossos mais afetados, em ordem decrescente, foram o carporradial, o terceiro osso cárpico, o rádio e o carpo intermédio. Quanto à localização da fratura, encontraram, em primeiro a borda distal do carporradial, em segundo a borda proximal do terceiro osso cárpico, em terceiro a equivalência entre a borda distal do rádio e a borda proximal do carporradial, em quarto a borda proximal do carpo intermédio e por último a borda distal deste mesmo osso. Os autores observaram ainda que, tanto para o membro quanto para o osso e para o local mais afetado, os resultados encontrados são semelhantes às informações da literatura consultada, o que permite concluir que as condições de traumatismo, às quais os cavalos estão submetidos durante os treinamentos e as corridas no Jockey Club Brasileiro, são semelhantes a de outros locais do mundo.

Palavras chave: eqüino; carpo; fraturas; radiologia

\section{Introdução}

As fraturas osteocondrais, na região rádio cárpica de cavalos Puro Sangue Inglês em atividade turfística, são um dos principais motivos de claudicação com conseqüente prejuízo econômico e de performance.

Park et al. (1970), analisando cavalos das raças Puro Sangue Inglês e Quarto de Milha, observaram que 50\% das fraturas cárpicas se localizam no osso carporradial, sendo a epífise distal do rádio, o carpo intermédio e o terceiro osso cárpico menos afetados. Quanto ao membro, assinalam o direito como o mais freqüentemente afetado. Thrall et al. (1971) examinaram, radiograficamente, 197 carpos de 141 cavalos Puro Sangue Inglês e observaram que $56,7 \%$ dos animais apresentam pelo menos uma fratura "chip", com percentual de $31,7 \%$ para a borda distal do carporradial, $20,3 \%$ para o terceiro osso cárpico, $17,9 \%$ para a epífise distal do rádio, $14,6 \%$ para o aspecto proximal do carporradial e $11,4 \%$ para o inter- médio do carpo. Mcllwraith et al. (1987) registraram a incidência de fraturas osteocondrais "chip" em 220 cavalos Puro Sangue Inglês. Observaram que o membro direito foi o mais afetado, que a borda distal do osso carporradial foi o local mais comumente afetado, seguido pela borda proximal do osso intermédio do carpo e pela borda látero distal do rádio; em $37 \%$ dos animais apareceram fraturas nos dois carpos. Stashak (1987) afirmou que a fratura "chip" é a mais comum e considera o carporradial, o terceiro osso cárpico e o osso intermédio do carpo, assim como a porção distal do rádio, os mais afetados. Quanto ao membro declarou não haver concordância na literatura. De Siqueira et al. (1993) trabalhando com 31 animais das raças Quarto de Milha e Puro Sangue Inglês, entre 2 e 5 anos encontraram 82 fraturas em 40 carpos. Destas 82,18 foram no carporradial, 33 distais de rádio, 30 no intermédio do carpo e uma no carpo ulnar. Quanto ao local, a borda distal do rádio foi o mais afetado (33/82), seguido pelo intermédio do carpo (30/82). A borda medial proximal, foi a área mais afetada. Observaram ainda uma predominância no membro esquerdo.

O presente trabalho tem por objetivo registrar a incidência e localização das fraturas osteocondrais "chip" na região rádio cárpica de cavalos Puro Sangue Inglês em atividade turfística no Jockey Club Brasileiro.

\section{Material e Métodos}

Foram utilizados 18 cavalos Puro Sangue Inglês, 14 machos e 4 fêmeas, com idade entre 2 e 6 anos, alojados no Jockey Club Brasileiro perfazendo um total de $30 \mathrm{ca}-$ sos de fraturas osteocondrais "chip" com radio-diagnóstico (Tabela 1).

As radiografias foram obtidas empregando-se chassis $24 \times 30 \mathrm{~cm}$ montados com ecran e filmes verdes. Para as tomadas dorso-palmar (DPa) e, quando necessárias, para as tangenciais (Skyline), utilizaram-se $70 \mathrm{KV}, 25 \mathrm{mAs}, 0,4 \mathrm{~s}$ e distância foco-filme de $80 \mathrm{~cm}$. Nas tomadas dorso medial-palmaro lateral oblíqüa (DM-PaLO), dorso lateralpalmaro medial oblíqüa (DL-PaMO), látero-medial (LM) e látero-medial flexionada (LM flexionada), empregaram-se $70 \mathrm{KV}, 25 \mathrm{mAs}, 0,3 \mathrm{~s}$ e distância foco-filme de $80 \mathrm{~cm}$.

\footnotetext{
${ }_{1}^{1}$ Faculdade de Medicina Veterinária, FIPLEI, Caluge $\mathrm{s} / \mathrm{n}^{\circ}$, Caixa Postal 112.449, 24800-000 Itaboraí, RJ, Brasil

2 Veterinária Equina Ltda., Vila Hípica $n^{\circ} 26$, Rua Gal. Garzon 62, 22470-010 Rio de Janeiro, RJ, Brasil

${ }^{3}$ Rua Visconde de Pirajá 447/601, 22410-003 Rio de Janeiro, RJ, Brasil
} 
Tabela 1 - Dados dos eqüinos estudados relacionando o membro afetado e o local da fratura

\begin{tabular}{|c|c|c|c|}
\hline № do caso & Anos/Sexo & Membro & Local da lesão \\
\hline 1 & $4 / F$ & D & DCR \\
\hline 2 & $4 / \mathrm{M}$ & $E$ & DCR \\
\hline 3 & $4 / \mathrm{M}$ & $E$ & DCR \\
\hline 4 & $2 / \mathrm{M}$ & D & DCR \\
\hline 5 & $2 / M$ & D & PIIIC \\
\hline 6 & $4 / M$ & $E$ & DR \\
\hline 7 & $2 / M$ & $E$ & DR \\
\hline 8 & $4 / M$ & $E$ & DCR \\
\hline 9 & $4 / M$ & D & PCR \\
\hline 10 & $4 / M$ & $\mathrm{D}$ & PIIIC \\
\hline 11 & $4 / \mathrm{M}$ & $D$ & DCR \\
\hline 12 & $6 / \mathrm{M}$ & D & DCR \\
\hline 13 & $6 / \mathrm{M}$ & $\mathrm{D}$ & PIIIC \\
\hline 14 & $3 / F$ & D & DCR \\
\hline 15 & $3 / F$ & $D$ & PIIIC \\
\hline 16 & $3 / \mathrm{M}$ & $E$ & PCR \\
\hline 17 & $3 / \mathrm{M}$ & $E$ & DCR \\
\hline 18 & $3 / \mathrm{M}$ & $\bar{D}$ & PCR \\
\hline 19 & $3 / \mathrm{M}$ & D & DCR \\
\hline 20 & $3 / \mathrm{M}$ & D & $\mathrm{DCl}$ \\
\hline 21 & $3 / \mathrm{M}$ & $\mathrm{D}$ & PIIC \\
\hline 22 & $5 / \mathrm{M}$ & $E$ & PCR \\
\hline 23 & $5 / \mathrm{M}$ & $\mathrm{E}$ & $\mathrm{PCl}$ \\
\hline 24 & $5 / \mathrm{M}$ & $E$ & DR \\
\hline 25 & $4 / \mathrm{M}$ & $\bar{D}$ & DCR \\
\hline 26 & $4 / M$ & $E$ & DCR \\
\hline 27 & $3 / F$ & $D$ & DCR \\
\hline 28 & $4 / \mathrm{M}$ & $\bar{E}$ & $\mathrm{DR}$ \\
\hline 29 & $4 / \mathrm{M}$ & $\bar{E}$ & $\mathrm{PCl}$ \\
\hline 30 & $2 / F$ & D & DCR \\
\hline
\end{tabular}

DCR: distal de carporradial; PCR: proximal de carporradial; PIIIC: proximal do terceiro osso cárpico; DR: distal de rádio; $\mathrm{DCl}$ : distal de carpo intermédio; $\mathrm{PCl}$ : proximal de carpo intermédio

\section{Resultados e Discussão}

O membro direito foi o mais afetado (Tabelas 2, 3), corroborando Park et al. (1970) e Mcllwraith et al. (1987).

O osso mais afetado foi o carporradial, seguido do terceiro osso cárpico, do rádio e do carpo intermédio (Tabela 2) resultados que concordam inteiramente com Thrall et al. (1971) e parcialmente com Park et al. (1970) com diferenças quanto ao terceiro e quarto ossos mais afetados respectivamente intermédio do carpo e rádio. Com Mcllwraith et al. (1987) apenas existe concordância quanto ao osso mais afetado. Stashak (1987) não explicou a ordem de ocorrência mas relacionou os mesmos ossos enquanto De Siqueira et al. (1993) apresentaram dados díspares com os ora obtidos e com os demais autores.
Quanto à localização da fratura encontra-se, em primeiro a borda distal do carporradial, em segundo a borda proximal do terceiro osso cárpico, em terceiro a equivalência entre a borda distal do rádio e a borda proximal do carporradial, em quarto a borda proximal do carpo intermédio e por último, a borda distal deste mesmo osso (Tabela 3). Só não existe concordância com De Siqueira et al. (1993) quanto ao local mais afetado. Considerando-se o segundo local mais afetado, percebe-se que os dados obtidos apenas conferem com os de Thrall et al. (1971), pois Park et al. (1970), Mcllwraith et al. (1987) e Stashak (1987) consideram a região distal do rádio (DR). Para o terceiro osso mais afetado, os resultados ora obtidos estão de acordo com Thrall et al. (1971) e De Siqueira et al. (1993).

Mason e Bourke (1973) citados por Stashak (1987), explicaram que para os animais que correm em sentido anti-horário, como os estudados no presente trabalho, durante a corrida, na curva, existe um aumento da força de concussão na superfície lateral dos membro interno (esquerdo) e na superfície medial do membro externo (direito), sendo aí a localização do maior índice de fraturas cárpicas. Também pode ser que, nas curvas, o cavalo reaja contra a força centrípeta apoiando mais peso no membro externo (direito). Auer (1980), citado por Stashak (1987), menciona que os cavalos freqüentemente desviam para o lado direito, quando nas retas, e que estão galopando no membro direito ao final da corrida, quando colocam um grande estresse sobre este membro na medida que ficam fatigados. Concorda-se que estes mecanismos de estresse sobre os membros possam realmente provocar as fraturas como as aqui observadas, fato que parcialmente justifica os resultados e a semelhança com os observados pelos autores consultados.

Com relação às disparidades observadas por De Siqueira et al. (1993), em relação ao membro mais afetado, pode ser que por trabalharem também com animais da raça Quarto de Milha, que muitas vezes correm em cancha reta, os fatores de apoio se modifiquem, assim como também o sentido de corrida para os Puro Sangue Inglês, uma vez que nos Estados Unidos temos corridas nos dois sentidos.

\section{Conclusões}

A semelhança dos resultados obtidos com os autores consultados permite concluir que as condições de traumatismo, às quais os cavalos estão submetidos durante os treinamentos e as corridas no Jockey Club Brasileiro, são semelhantes àquelas de outros locais do mundo.

Tabela 2 - Incidência de fraturas osteocondrais "chip" em eqüinos com relação aos ossos mais afetados

\begin{tabular}{lclcc}
\hline Osso & $\begin{array}{l}\text { Incidência } \\
\text { absoluta }\end{array}$ & $\begin{array}{l}\text { Incidência } \\
\text { relativa (\%) }\end{array}$ & $\begin{array}{l}\text { Membro } \\
\text { direito }\end{array}$ & $\begin{array}{l}\text { Membro } \\
\text { esquerdo }\end{array}$ \\
\hline Rádio & 4 & 13,34 & 1 & 3 \\
Carporradial & 18 & 60 & 12 & 6 \\
Carpo & 3 & 10 & 1 & 2 \\
$\begin{array}{l}\text { Intermediário } \\
\text { Terceiro osso cárpico }\end{array}$ & 5 & 16,66 & 5 & - \\
\hline Total & 30 & 100 & $19(63,34 \%)$ & $11(36,66 \%)$ \\
\hline
\end{tabular}


Tabela 3 - Incidência de fraturas osteocondrais "chip" em eqüinos com a localização específica

\begin{tabular}{lllcc}
\hline Osso & $\begin{array}{l}\text { Incidência } \\
\text { absoluta }\end{array}$ & $\begin{array}{l}\text { Incidência } \\
\text { relativa (\%) }\end{array}$ & $\begin{array}{l}\text { Membro } \\
\text { direito }\end{array}$ & $\begin{array}{l}\text { Membro } \\
\text { esquerdo }\end{array}$ \\
\hline Rádio & distal & 13,34 & 1 & 3 \\
Carporradial & proximal & 13,34 & 2 & 2 \\
& distal & 46,66 & 10 & 4 \\
Carpo & proximal & 6,66 & - & 2 \\
Intermediário & distal & 3,34 & 1 & - \\
Terceiro osso cárpico & proximal & 16,66 & 5 & - \\
\hline Total & & 100 & $63,34 \%$ & $36,66 \%$ \\
\hline
\end{tabular}

\section{Abstract \\ Incidence and locations of osteochondral chip frac- tures in Thoroughbred racing horses' carpus}

The incidence and location of 30 cases of osteochondral chip fractures in equine carpus of Thoroughbred racing horses between 2 and 6 years of age were registered. This study showed that the right limb was the most affected one and, in a decreasing order, os carpi radiale, os carpale III, os radii and os carpi intermedium were the most affected bones. Concerning the location of chip fractures, also in a decreasing order of incidence, the distal edge of the os carpi radiale, proximal edge of os carpale III, equivalence between the distal edge of os radii and proximal edge of os carpi radiale, proximal edge of os carpi intermediumi and distal edge of the same bone were reported. Comparing to the literature review, similar results were obtained at the present study including both limb and bones and respective affected areas described. This allows the authors to conclude that the traumatic conditions to which the horses are submited during the training and racing are similar to those found in other racing centers around the world.

Key words: equine; carpus; fractures; radiology

\section{Referências bibliográficas}

DE SIQUEIRA, L. F. G., COLLIER, M. A., HENRY, G. A., NEUMAN, M. Chip fractures of the intermediate carpal bone in the horse: correlation between radiographic and arthroscopic findings. J. E. Vet. Sci., v. 13, n. 4, p. 190-192, 1993.

MCILWRAITH, C. W., YOVICH, J. V., MARTIN, G. S. Arthroscopic surgery for the treatment of osteochondral chip fractures in the equine carpus. J. Am. Vet. Med. Assoc., v. 191, n. 5, p. 531-540, 1987.

PARK, R. D., MORGAN, J. P., O'BRIEN, T. Chip fracture in the carpus of the horse: a radiographic study of their incidence and locations. J. Am. Vet. Med. Assoc., v. 157, n. 10, p. 13051312. 1970.

STASHAK, T. S. Adams'lameness in horses. Philadelphia: Lea \& Febiger, 1987. 906 p. Cap. 8, p. 647-648.

THRALL, D. E., LEBEL, J. L., O'BRIEN, T. A five-year survey of the incidence and location of equine carpal chip fractures. J. Am. Vet. Med. Assoc., v. 158, n. 8, p. 1366-1368, 1971. 